\title{
Development and application of an indirect ELISA for the detection of antibodies to porcine epidemic diarrhea virus based on a recombinant spike protein
}

\author{
Huixing Lin ${ }^{1}$, Hong Zhou' ${ }^{1}$ Lu Gao ${ }^{1}$, Bin Li ${ }^{2}$, Kongwang He ${ }^{2}$ and Hongjie Fan ${ }^{1,3^{*}}$
}

\begin{abstract}
Background: As the major causative agent of swine viral diarrhea, porcine epidemic diarrhea virus (PEDV) has caused massive losses to the economies of swine raising countries. Accordingly, the serological detection of corresponding antibodies would be beneficial to diagnose PEDV indirectly to control the disease. In this study, an indirect enzyme-linked immunosorbent assay (ELISA) based on the recombinant truncated spike (S) protein of PEDV was developed and validated.

Results: The reaction conditions of the developed indirect ELISA were optimized. This indirect ELISA was compared to indirect immunoinfluscent assay (IFA), and the overall coincidence rate was $96.74 \%$ based on testing 368 clinical serum samples with different PEDV antibody levels. No cross-reactivity with other common swine pathogens was detected for the developed S1 indirect ELISA. Finally, the S1 indirect ELISA was applied to detect serum antibodies of 3304 field samples collected from different pig farms in eastern China, and it presented an overall substantial agreement on the PEDV infection status.
\end{abstract}

Conclusions: This established S1 indirect ELISA is capable of detecting serum antibodies against PEDV, and due to its high sensitivity and specificity, it could be applied for serological evaluation and indirect diagnosis of PEDV infection.

Keywords: Porcine epidemic diarrhea virus, Spike protein, ELISA

\section{Background}

Porcine epidemic diarrhea (PED) is a highly contagious swine enteritis caused by porcine epidemic diarrhea virus (PEDV), which belongs to the order Nidovirales and family Coronaviridae. The typical symptoms of PED are diarrhea, vomiting, and dehydration, which can be especially dangerous to suckling piglets $[1,2]$. The mortality of neonatal piglets younger than 5 days old can approach 100\% [3-5]. PED first appeared in Britain in

\footnotetext{
* Correspondence: fhj@njau.edu.cn

${ }^{1}$ MOE Joint International Research Laboratory of Animal Health and Food Safety, College of Veterinary Medicine, Nanjing Agricultural University, Nanjing 210095, China

${ }_{3}^{3}$ Jiangsu Co-Innovation Center for the Prevention and Control of Important Animal Infectious Diseases and Zoonoses, Yangzhou University, Yangzhou 225009, China

Full list of author information is available at the end of the article
}

1971, followed by an outbreak of diarrhea in several pig farms in Belgium in 1977 [6]. These outbreaks led to identification of a coronavirus-like particle named CV777, which is now recognized as the classic PEDV strain. In recent years, PED epidemics have become prevalent in swine-raising countries in Asia, including South Korea, China, Japan, and Vietnam, and can cause enormous economic loss $[7,8]$.

PEDV is a single-stranded RNA virus composed primarily of four structural proteins: the spike protein $(\mathrm{S}$, $180-220 \mathrm{kDa})$, membrane protein $(\mathrm{M}, 27-32 \mathrm{kDa})$, envelope protein $(\mathrm{E}, 7 \mathrm{kDa})$ and nucleocapsid protein $(\mathrm{N}$, $55-58 \mathrm{kDa}) . \mathrm{S}$ protein is located on the surface of the virus particle. It is categorized as a type I membrane fusion protein and has the significant biological effect of binding to target cell receptors and entering the cell

(c) The Author(s). 2018 Open Access This article is distributed under the terms of the Creative Commons Attribution 4.0 International License (http://creativecommons.org/licenses/by/4.0/), which permits unrestricted use, distribution, and 
through plasma membrane fusion $[9,10]$. The $S$ protein has higher antigenicity than any of the other PEDV proteins, and anti-S antibodies detected in PEDV-infected pigs persist longer than anti- $\mathrm{N}$ antibodies [11]. The $\mathrm{S}$ protein can be separated into the S1 (1-789 aa) subunit and the S2 (790-1383 aa) subunit [12]. The S1 subunit is the extracellular domain and can recognize and bind to target cell receptors [13], and it is closely linked to the formation of neutralizing antibodies. Therefore, this study selected a gene fragment within the S1 subunit as a coating antigen to develop an indirect enzyme-linked immunosorbent assay (ELISA) method for the detection of PEDV antibodies.

\section{Methods}

\section{Materials}

The PEDV YC2014 strain was isolated on a breeding farm in Yancheng city in 2014 (GenBank: KU252649.1). The prokaryotic expression vector pET-28a(+) was purchased from BioVector NTCC Inc. (Beijing, China). The HRP-goat anti-pig IgA, HRP-goat anti-pig IgG, and FITC-goat anti-pig IgA was purchased from Abcam plc. (Shanghai, China). The standard PEDV negative serum were collected from specific pathogen free (SPF) pigs. The standard PEDV positive serum were collected from experimentally PEDV immunized SPF pigs, at 7, 14, 21, 28, 35, 42 and 49 day post-inoculation (dpi). These standard serum were identified of PEDV-specific antibodies positive by both indirect immunoinfluscent assay (IFA) and seroneutralization assay (SN) as previously described [14, 15]. The swine PoRV antibody ELISA kit and the swine TGEV ELISA kit were obtained from Ingenasa (Madrid, Spain).

\section{Construction of the recombinant plasmid}

The gene sequence of truncated spike protein (named S1) was amplified from the genomic RNA of PEDV YC2014 strain (Genbank: KU252649.1) by reverse-transcriptase (RT)-PCR. The forward primer was 5' CGCGGAT CCGTCACTAGGTGCCAGTCCACTATTAA-3'and the reverse primer was 5'-CCCAAGCTTTCAATTGTAAA TATCCACTTTAAGAAAACAATAA-3'. Underlined portions represent BamH I and Hind III restriction sites, respectively. The target gene was $1068 \mathrm{bp}$ in length and subcloned into the prokaryotic expression vector pET-28a (+), then transformed into a strain of competent E. coli cells, DH5 $\alpha$. Transformed colonies were selected from Luria-Bertani (LB) agar plates containing kanamycin $(50 \mu \mathrm{g} / \mathrm{mL})$ and were identified by PCR. The resulting recombinant expression plasmid was named 28a-S1 and was identified by double enzyme digestion and DNA sequence analysis. Subsequently, the recombinant expression plasmid 28a-S1 was transformed into E. coli BL21 (DE3).

\section{Expression and purification of the recombinant protein} S1 The positive transformants were cultured in LB medium containing $50 \mu \mathrm{g} / \mathrm{mL}$ kanamycin with vigorous shaking at $37{ }^{\circ} \mathrm{C}$ until the $600 \mathrm{~nm}$ optical density $\left(\mathrm{OD}_{600}\right)$ of bacteria cultures reached approximately 0.5 . Then, by adding isopropyl- $\beta$-D-thiogalactopyranoside (IPTG), the recombinant protein $\mathrm{S} 1$ was induced for $6-8 \mathrm{~h}$ at $37{ }^{\circ} \mathrm{C}$. The expression of recombinant proteins was analyzed by $12 \%(v / v)$ sodium dodecyl sulfate-polyacrylamide gel electrophoresis (SDS-PAGE) and the gels were stained with coomassie brilliant blue. Induced cells were pelleted and washed in phosphate-buffered saline (PBS) three times, then lysed by sonication in an ice-water bath. The lysed cells were centrifuged at 12,000 g for $10 \mathrm{~min}$, then the precipitate (inclusion body) was dissolved with binding buffer containing $8 \mathrm{M}$ urea. The supernatant and the precipitate were then subjected to SDS-PAGE analysis. The recombinant protein was purified through affinity chromatography using a Ni-NTA spin column following the manufacturer's recommendations.

\section{Western blotting}

Purified recombinant protein S1 was subjected to $12 \%$ $(v / v)$ SDS-PAGE, and the gel was prepared for western blotting as follows. Recombinant proteins separated in the gel were electrically transferred to a nitrocellulose membrane and the membrane was blocked overnight at $4{ }^{\circ} \mathrm{C}$ with Tris-buffered saline containing Tween-20 (TBST) which contained 5\% $(w / v)$ skimmed milk powder. The composition of TBST is as follows: $20 \mathrm{mM}$ Tris- $\mathrm{HCl}, 150 \mathrm{mM} \mathrm{NaCl}$, and $0.05 \%$ Tween-20. The membrane was then incubated with pig anti-PEDV polyclonal antibody (1:300 dilution in blocking buffer) for $1 \mathrm{~h}$ at $37^{\circ} \mathrm{C}$ on a plate shaker. Following this incubation, the membrane was washed three times with TBST buffer and reacted with HRP-goat anti-pig IgG (1:2000 dilution in TBST) at $37{ }^{\circ} \mathrm{C}$ for $45 \mathrm{~min}$. After three washes, the final color reaction was developed with a solution of 3,3' -Diaminobenzidine (DAB).

\section{Recombinant protein S1 indirect ELISA}

Conventional indirect ELISA was performed with the following steps. ELISA plates with 96 wells (Costar, USA) were coated with $100 \mu \mathrm{L}$ purified recombinant S1 protein in bicarbonate buffer $(\mathrm{pH}=9.6)$ for $2 \mathrm{~h}$ at $37^{\circ} \mathrm{C}$. Then, plates were washed three times with PBST (PBS containing $0.05 \%$ Tween-20) and blocked with 5\% skimmed milk in PBS for $2 \mathrm{~h}$ at $37{ }^{\circ} \mathrm{C}$. After plates were washed, $100 \mu \mathrm{L}$ porcine serum samples diluted in PBS containing 5\% $(\mathrm{w} / \mathrm{v})$ skimmed milk was added and incubated for $45 \mathrm{~min}$ at $37{ }^{\circ} \mathrm{C}$. Plates were washed four times and reacted with $100 \mu \mathrm{L}$ diluted secondary antibody (HRP-goat anti-pig IgA or HRP-goat anti-pig IgG) for 
30 min at $37{ }^{\circ} \mathrm{C}$ for the purpose of detecting $\operatorname{IgA}$ or $\operatorname{IgG}$ against PEDV in serum samples. Plates were then washed four times and $100 \mu \mathrm{L}$ tetramethylbenzidine (TMB) substrate solution was added to each well for a chromogenic reaction at room temperature for $15 \mathrm{~min}$ in complete darkness. The color reaction was stopped by the addition $50 \mu \mathrm{L}$ of $2 \mathrm{M} \mathrm{H}_{2} \mathrm{SO}_{4}$ to each well. Finally, the $\mathrm{OD}_{450}$ was measured and recorded immediately using an Infinite 200 PRO microplatereader (Tecan, Männedorf, Switzerland).

The optimal dilution of recombinant protein S1 and standard serum was determined by a checkerboard titration based on the method mentioned above. Briefly, the concentration of $\mathrm{S} 1$ protein was gradually reduced in the following series: $10,7.5,5,2.5,1.0$, and $0.5 \mu \mathrm{g} / \mathrm{mL}$. The standard PEDV positive and negative serum were serially diluted in a 2-fold series from 1:20 to 1:320. When the $\mathrm{OD}_{450}$ ratio of positive serum to negative serum was highest, and the $\mathrm{OD}_{450}$ of positive serum was closest to 1.0, the corresponding dilutions of coated antigen and serum sample were considered optimal. In addition to optimal protein dilution, the coating conditions, blocking solution, and reaction time of various materials was explored. Furthermore, the optimal concentration of HRP-goat anti-pig IgA was tested using the following dilutions: 1:2000, 1:5000, 1:10000, 1:15000, and 1:20000.

\section{Determination of the cut-off value}

Two hundred and seventy serum samples were collected for the purpose of determining the positive-negative cut-off value, of which 90 serum samples were collected from 90 SPF pigs, 180 serum samples were collected from grow-finish pigs from five farms between 2009 and 2012. These five farms were located in areas with no previous history of enteric signs compatible with viral diarrhea, and were PEDV RNA negative by real-time RT-PCR based on a single collection. These serum samples were confirmed PEDV-negative by both IFA and SN assays as previously described [14, 15], and then were used to define the cut-off value in the S1 indirect ELISA. The $\mathrm{OD}_{450}$ value of these PEDV-negative serum samples obtained in this S1 indirect ELISA were recorded to calculate the cut-off value. The mean $\mathrm{OD}_{450}$ value of these negative samples $(\mathrm{N})+3 \times$ standard deviations $(\mathrm{SD})$ was defined as the cut-off value. Serum samples showing $\mathrm{OD}_{450}$ value greater than or equal to this cut-off were considered PEDV-seropositive.

\section{Assessment of S1 indirect ELISA}

To assess the accuracy of this developed S1 indirect ELISA, 368 serum samples from different pig farms were tested using this ELISA method. As a comparison, IFA was applied to test these samples and act as a reference method to distinguish positive or negative samples.
Briefly, Vero cells grown on 96-well plates were infected with the PEDV YC2014 strain at multiplicity of infection (m. o. i) of 5. At $48 \mathrm{~h}$ post-infection, cells were washed three times with PBST and fixed with cold methanol for $10 \mathrm{~min}$ at $-20{ }^{\circ} \mathrm{C}$. Cells were then washed three times with PBST and blocked with $10 \%$ bovine serum albumin (BSA) at $37{ }^{\circ} \mathrm{C}$ for $1 \mathrm{~h}$. After been double diluted for six consecutive dilutions in dilution buffer (1\% BSA in PBST), the 368 serum samples with varied PEDV antibody status were added in the wells of 96-well plate, and were incubated for $1 \mathrm{~h}$ at $37^{\circ} \mathrm{C}$. After three washes with PBST, cells were treated with a FITC-conjugated goat anti-pig IgA (Thermo Scientific) at a 1:500 dilution with PBS for 30 min at $37{ }^{\circ} \mathrm{C}$. After a final four washes with PBST, all wells were examined using fluorescence microscopy (Axio Observer Z1, Zeiss, Germany). The PEDV antibody titers of the serum samples were expressed as the highest dilution of serum samples producing green fluorescent in the wells of 96-well plates.

The results of this two methods were compared, and the sensitivity and specificity of detection were calculated to evaluate the accuracy of the S1 indirect ELISA. Sensitivity was defined as the ratio of positive tests from the developed S1 indirect ELISA to the positive tests from the IFA. Specificity was defined as the ratio of negative tests from the developed ELISA to the negative tests from the reference IFA.

\section{Serum cross-reactivity of S1 indirect ELISA to other pathogens}

To validate the cross-reactivity, this S1 indirect ELISA was utilized to test porcine serum positive for other swine pathogens, namely, porcine transmissible gastroenteritis virus (TGEV), swine rotavirus (PoRV), porcine kobuvirus (PKV), porcine bocavirus (PBoV), porcine norovirus (PNoV), porcine circovirus type 2 (PCV2), porcine reproductive and respiratory syndrome virus (PRRSV), and enterotoxigenic E. coli (ETEC), Jerson Prand of the small intestine, Clostridium Welchii Type C. The positive sera were prepared by our lab, by immunizing the specific pathogen free (SPF) piglets with purified virus or bacteria. Thirty positive serum samples for each virus were tested, and each sample was repeated in triplicate.

\section{Determination of repeatability of S1 indirect ELISA}

To test the repeatability of this ELISA, 255 serum samples with different PEDV antibody levels were chosen. For inter-assay variability, each sample was tested in 5 replicates on plates of different occasions. For intra-assay variability, each sample was tested in 5 replicates on plates within the same occasion. The results were presented as the coefficient of variation (CV), which is the ratio of the standard deviation (SD) to the mean $\mathrm{OD}_{450}$ value of each 
group of samples (S). A CV value criterion of $10 \%$ was used to meet the repeatability requirement of the test.

\section{PEDV antibody detection of field serum samples}

This S1 indirect ELISA was applied to seroepidemiological analysis of a total of 3304 clinical swine serum samples collected from thirty seven farms in eastern China. The PEDV infection status of a given farm was determined based on demonstration of PEDV RNA in fecal samples by real-time RT-PCR and presence of enteric signs [16]. One thousand one hundred and twenty five serum samples were collected from nursery and grow-finish pigs from ten farms between 2011 and 2015 at 3-6 weeks after the start of PEDV outbreaks in these farms. Four hundred and eighty two serum samples were collected from nursery and grow-finish pigs from five farms between 2012 and 2015. These five farms were located in areas with no previous history of enteric signs compatible with viral diarrhea, were PEDV RNA negative by real-time RT-PCR based on a single collection, and were considered non-exposed to PEDV. Three hundred and forty four serum samples from nursery pigs without PEDV exposure were collected from six farms between 2011 and 2015. These samples were confirmed to be positive for anti-PoRV antibodies (3 farms, $n=149$ ) or anti-TGEV antibodies ( 3 farms, $n=195$ ) by both IFA and commercial ELISA kits (obtained from Ingenasa). One thousand three hundred and fifty three porcine serum samples with unknown PEDV exposure status were randomly selected from sixteen farms from nursery and grow-finish pigs between 2011 and 2014.

\section{Results}

Subcloning, inducible expression and purification of recombinant S1 protein

The gene of PEDV truncated S1 fragment (67-1134 nt) was amplified by RT-PCR (Fig. 1a). A 1068 bp PCR product was obtained and subcloned to prokaryotic
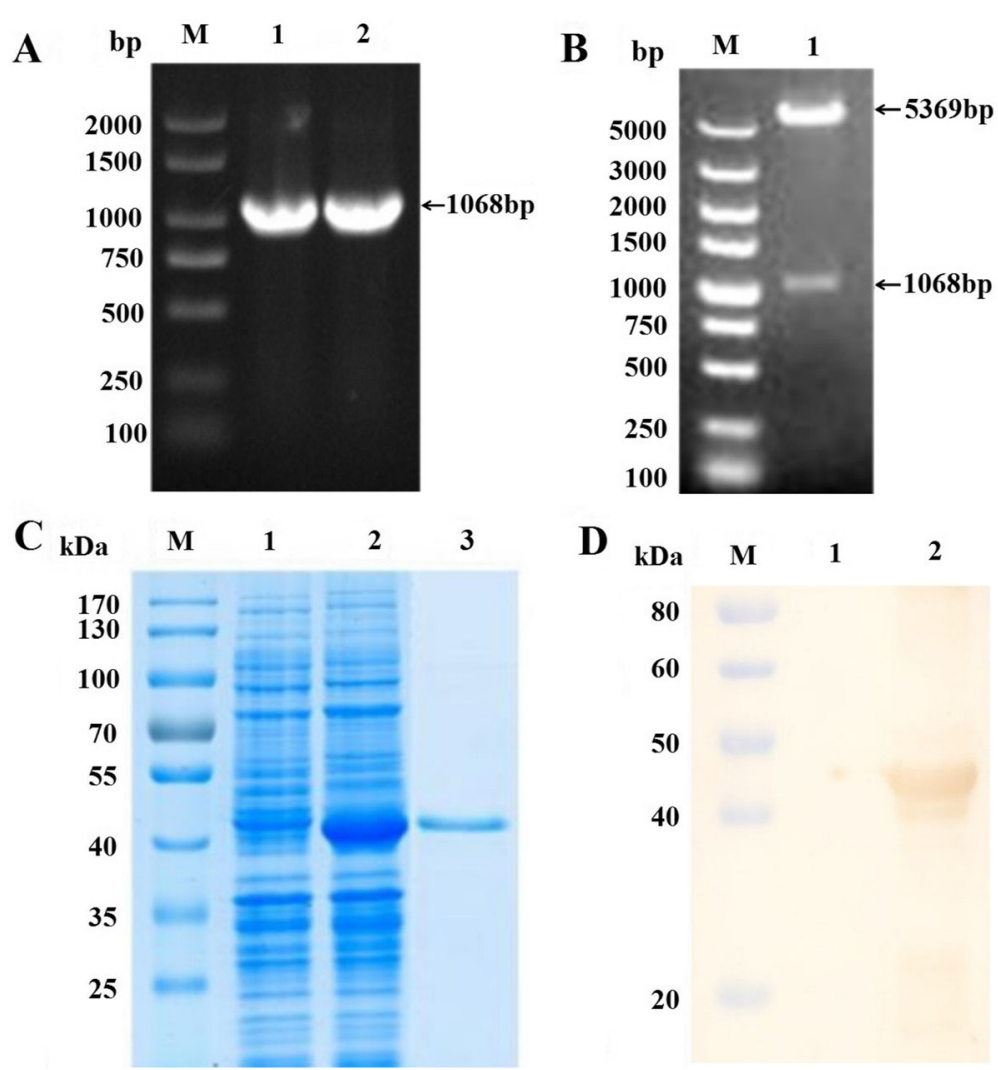

D

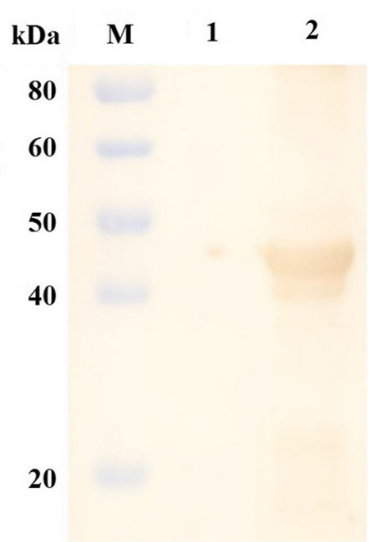

Fig. 1 Amplification, SDS-PAGE and western blotting analysis of the recombinant protein S1. a RT-PCR amplification of the truncated S1 gene fragment. Lane M, DL2000 DNA marker. Lane 1 and 2, the truncated S1 gene fragment. b Identifiction of the recombinant expression plasmid 28a-S1 by double enzyme digestion. Lane M, DL5000 DNA marker. Lane 1, the recombinant expression plasmid 28a-S1 digested by BamH I/Sal I. c SDS-PAGE analysis of S1 protein. Lane M, prestained protein molecular weight standard. Lane 1, transformed cells of BL21/pET-28a(+) after IPTG induction for $6 \mathrm{~h}$. Lane 2, transformed cells of BL21/28a-S1 after IPTG induction for $6 \mathrm{~h}$. Lane 3, purified recombinant protein S1 by affinity chromatography of Ni-NTA spin column. d Western blotting analysis of S1 protein. Lane M, prestained protein molecular weight standard. Lane 1, E. coli BL21 with empty vector pET-28a(+) reacted with polyclonal mouse anti-PEDV antibody. Lane 2, purified S1 protein reacted with polyclonal mouse anti-PEDV antibody. A prominent band with the expected size $42 \mathrm{kDa}$ appeared after incubation 
expression vector $\mathrm{pET}-28 \mathrm{a}(+)$, and the inserted gene was sequenced to ensure the correctness of the reading frame. As shown by SDS-PAGE (Fig. 1c), the recombinant protein $\mathrm{S} 1$ was expressed in the form of inclusion body, resulting in a $6 \times$ His-tag fusion protein whose molecular mass was approximately $42 \mathrm{kDa}$. Sonicated lysates from recombinant $E$. coli were harvested, and the precipitate was dissolved in $8 \mathrm{M}$ urea and purified by affinity chromatography of $\mathrm{Ni}^{2+}$-NTA agarose. The immunoreactivity of S1 protein was examined by western blotting. An obvious band revealed that $\mathrm{S} 1$ protein was specifically bound by pig anti-PEDV polyclonal antibody (Fig. 1d).

\section{Optimization of S1 indirect ELISA}

As expected with checkerboard titration, with concentrations of antigen and serum regularly decreasing, absorbance values of corresponding samples declined. The optimal dilution of coated antigen S1 protein was measured at $0.25 \mu \mathrm{g} /$ well $(2.5 \mu \mathrm{g} / \mathrm{mL})$, and optimal serum sample dilution was 1:40 (Table 1). Furthermore, other reaction conditions of the developed ELISA were optimized. In brief, the optimum coating condition was $2 \mathrm{~h}$ at $37{ }^{\circ} \mathrm{C}$. The best blocking solution was selected as $5 \%$ skimmed milk in PBS. The optimal reaction times for serum, secondary antibodies, and TMB solution were $45 \mathrm{~min}, 30 \mathrm{~min}$ and $15 \mathrm{~min}$, respectively. Finally, the best working dilution of the HRP-goat anti-pig IgA was 1:10,000.

\section{Determination of the cut-off threshold value}

To determine the cut-off value of the S1 indirect ELISA, 270 PEDV-seronegative samples, verified by both IFA and SN assays, were tested by this ELISA method. The average optical density of these negative serum samples
(N) was calculated as 0.185 , and the standard deviation (SD) of these samples was 0.0337. Consequently, the cut-off threshold value of S1 indirect ELISA was calculated to be 0.286 , indicating that the sample $\mathrm{OD}_{450} \geq$ 0.286 was identified as PEDV-seropositive and vice versa.

\section{S1 indirect ELISA validation}

This developed S1 indirect ELISA was applied to 368 serum samples with varied PEDV antibody status (Table 2). In these samples, the S1 indirect ELISA detected 213 PEDV-positive samples, of which 206 tested PEDV-positive by IFA. On the other hand, of the remaining 155 samples that tested PEDV-seronegative by this S1 indirect ELISA, 150 of them were tested PEDV-negative by IFA. Hence, the sensitivity of S1 indirect ELISA was $96.71 \%$ among PEDV-seropositive individuals, and the specificity was $96.77 \%$ among PEDV-seronegative individuals using IFA as standard evaluation method. In summary, the overall coincidence rate of the S1 indirect ELISA to IFA was $96.74 \%$.

\section{Cross-reactivity of S1 indirect ELISA}

To test the cross-reactivity of this S1 indirect ELISA, other viruses known to cause swine diarrhea were examined. The average $\mathrm{OD}_{450}$ of positive serum samples for TGEV, PoRV, PKV, PBoV, PNoV, PCV2, PRRSV, ETEC, Jerson Prand of the small intestine, and Clostridium Welchii Type C were 0.193, 0.121, 0.098, 0.147, 0.150, $0.182,0.178,0.188,0.145$ and 0.124 , respectively. The results showed that these serum samples were PEDV-seronegative and non-cross-reactive with this S1 indirect ELISA, indicating that the established ELISA was an effective method for detecting PEDV antibodies.

Table 1 Checkerboard titration of the recombinant protein S1

\begin{tabular}{|c|c|c|c|c|c|c|}
\hline \multirow{2}{*}{$\begin{array}{l}\text { OD450 ratio }(\mathrm{P} / \mathrm{N}) \\
\mathrm{P} / \mathrm{N}\end{array}$} & & \multicolumn{5}{|c|}{ Dilution of serum sample } \\
\hline & & $1: 20$ & $1: 40$ & $1: 80$ & $1: 160$ & $1: 320$ \\
\hline \multirow[t]{12}{*}{ Concentrations of antigen $(\mu \mathrm{g} / \mathrm{mL})$} & 10 & $1.233 / 0.185$ & $0.980 / 0.100$ & $0.730 / 0.082$ & $0.551 / 0.052$ & $0.401 / 0.041$ \\
\hline & & 6.665 & 9.80 & 8.902 & 10.596 & 9.780 \\
\hline & 7.5 & $1.118 / 0.150$ & $0.942 / 0.092$ & $0.631 / 0.075$ & $0.459 / 0.047$ & $0.309 / 0.029$ \\
\hline & & 7.453 & 10.239 & 8.413 & 9.766 & 10.655 \\
\hline & 5.0 & $1.102 / 0.141$ & $0.854 / 0.077$ & $0.591 / 0.067$ & $0.388 / 0.042$ & $0.228 / 0.022$ \\
\hline & & 7.816 & 11.091 & 8.821 & 9.238 & 10.364 \\
\hline & 2.5 & $1.032 / 0.120$ & $0.832 / 0.073$ & $0.547 / 0.063$ & $0.335 / 0.040$ & $0.195 / 0.019$ \\
\hline & & 8.600 & 11.397 & 8.683 & 8.375 & 10.263 \\
\hline & 1.0 & $0.927 / 0.112$ & $0.753 / 0.071$ & $0.473 / 0.057$ & $0.316 / 0.037$ & $0.183 / 0.017$ \\
\hline & & 8.277 & 10.606 & 8.298 & 8.541 & 10.765 \\
\hline & 0.5 & $0.818 / 0.103$ & $0.714 / 0.068$ & $0.447 / 0.055$ & $0.292 / 0.033$ & $0.171 / 0.016$ \\
\hline & & 7.942 & 10.500 & 8.127 & 8.848 & 10.688 \\
\hline
\end{tabular}


Table 2 Comparison of the S1 indirect ELISA with the IFA

\begin{tabular}{llclll}
\hline & & \multicolumn{3}{l}{ IFA results } \\
\cline { 3 - 5 } & & Positive & Negative & Total \\
\hline S1 indirect ELISA results & Positive & 206 & 7 & 213 \\
& Negative & 5 & 150 & 155 \\
& Total & 211 & 157 & 368 \\
Data analysis & Sensitivity & $96.71 \%$ & & \\
& Specificity & & $96.77 \%$ & \\
& Coincidence rate & & & $96.74 \%$
\end{tabular}

\section{The repeatability of S1 indirect ELISA}

Intra-assay variability of the $\mathrm{S} 1$ indirect ELISA was assessed by testing 255 swine serum samples, each with 5 replicates. This analysis produced CVs ranging from $2.2-3.7 \%$, with an average value of $2.8 \%$. Inter-assay variability of four batches using identical samples produced CVs ranging from $2.6-4.5 \%$, with an average value of $3.2 \%$. The results demonstrated that this ELISA method yielded low levels of variation, and its repeatability was in the credible range.

\section{PEDV antibody detection of field serum samples}

This S1 indirect ELISA method was used on 3304 swine serum samples of different PEDV exposure status collected from 37 farms (Table 3). In the 10 farms from which 1125 samples were collected during the PEDV outbreaks between 2011 and 2015, 1027 samples were tested PEDV antibody positive, the positive detection varied from 78 to $100 \%$ between 10 farms. In the 5 PEDV non-exposed farms from which 482 samples were collected between 2012 and 2015, 31 samples were tested PEDV antibody positive, the positive detection varied from 5.1 to $7.8 \%$ between 5 farms. Among PoRV or TGEV antibody positive serum samples, 16/149 anti-PoRV antibody positive sample and 27/195 anti-TGEV antibody positive samples were tested PEDV antibody positive. In the 16 farms from which 1353 samples with unknown PEDV exposure status were collected between 2011 and 2014, 491 samples were tested PEDV antibody positive, the positive detection varied from 15 to $47 \%$ between 16 farms.

\section{Comparation of $\lg \mathrm{A}$ with $\lg \mathrm{G}$ in the sera of PEDV immunized pigs}

This S1 indirect ELISA was applied to test the sera of PEDV immunized pigs at 7, 14, 21, 28, 35, 42 and 49 day post-inoculation (dpi). The results (Fig. 2) showed that, both the IgA and the IgG were positive at $7 \mathrm{dpi}$. At early infection stage (7 dpi), the IgA titer was significantly higher than the IgG titer; at 14 dpi the IgA titer was equivalent to the IgG titer; and after $21 \mathrm{dpi}$, the IgA titer was significantly lower than the IgG titer. The IgG could exist in the sera of infection recovered stage for more time than IgA.

\section{Discussion}

Since December 2010, a large-scale outbreak of diarrhea has been observed in swine farms in China. Accumulated evidence indicates that this large-scale outbreak of diarrhea were caused by highly virulent PEDV variants $[17,18]$. Serological assays can quickly detect large numbers of samples with both high sensitivity and specificity. Several indirect ELISA have been developed based on either whole PEDV preparations or recombinant viral proteins [19-21]. The $S$ protein of PEDV has numerous epitopes and highly antigenic index regions that induce the production of neutralizing antibodies [10, 22, 23], and anti-S antibodies detected in PEDV-infected pigs persist longer than anti- $\mathrm{N}$ antibodies [11], thus, we choose $\mathrm{S}$ protein as the diagnostic antigen.

The recombinant $\mathrm{S} 1$ protein was applied to establish an indirect ELISA, and its reaction conditions were optimized. As PEDV is an enteric virus, it directly infects and damages enterocytes. Mucosal IgA, but not systemic IgG, plays a crucial role in protection $[24,25]$. In this research, the titers of IgA in the serum were tested for serological evaluation and indirect diagnosis of PEDV infection. Of the 1125 serum samples which were PEDV exposed, the overall positive rate of the antibody is $91.29 \%$, which were varied from 78 to $100 \%$ between 10 farms. Of the 482 serum samples which were PEDV non-exposed, the overall positive rate of the antibody is $6.43 \%$, which were varied from 5.1 to $7.8 \%$ between 5 farms. The evaluated ELISA presented an overall substantial agreement on the PEDV infection status of the field swine serum samples.

Table 3 Detection rates of anti-PEDV antibodies in field serum samples

\begin{tabular}{|c|c|c|c|c|}
\hline PEDV exposure & PoRV/TGEV exposure & No. samples & No. positive & Positive rate \\
\hline Exposed & Non-exposed & 1125 & 1027 & $91.29 \%$ \\
\hline Non-exposed & Non-exposed & 482 & 31 & $6.43 \%$ \\
\hline Non-exposed & Exposed & 149 & 16 & $10.74 \%$ \\
\hline Non-exposed & Exposed & 195 & 27 & $13.85 \%$ \\
\hline Unknown & Unknown & 1353 & 491 & $36.29 \%$ \\
\hline
\end{tabular}

Samples were collected from farms with known or unknown PEDV exposure as determined by real-time RT-PCR of fecal samples 


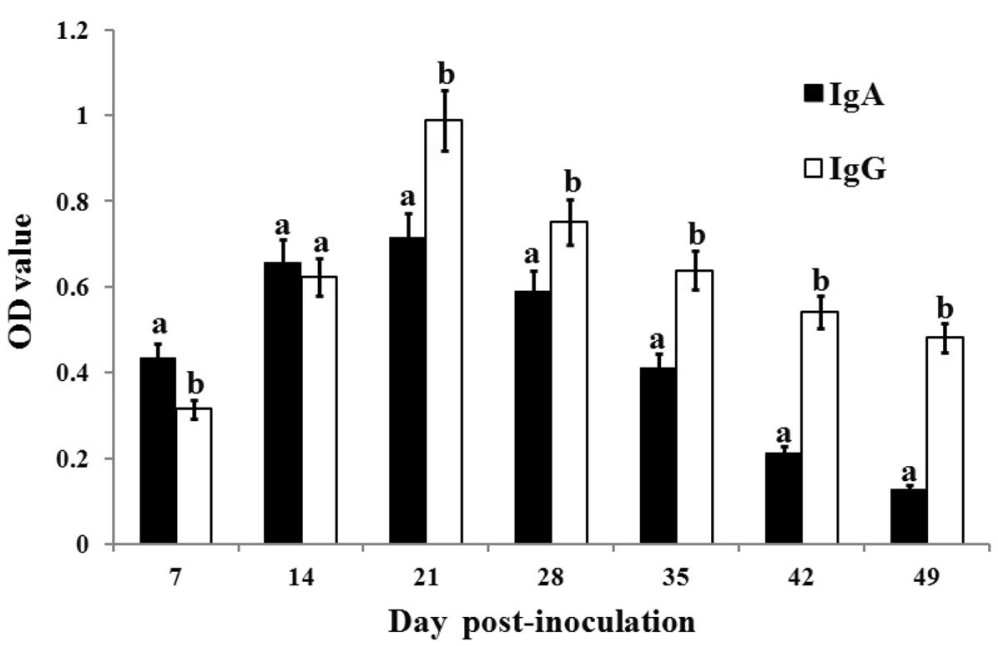

Fig. 2 Determination of IgA and IgG in the sera of PEDV immunized pigs. The sera of PEDV immunized pigs were tested by this S1 indirect ELISA at $7,14,21,28,35,42$ and 49 day post-inoculation (dpi). Both the IgA and the IgG were positive at $7 \mathrm{dpi}$. The $\lg$ could exist in the sera for longer time than IgA. Different letters ( $\mathbf{a}$, and $\mathbf{b}$ ) indicate significant difference between the groups

The intra- and inter-assay variability tests proved that this ELISA method had good repeatability. When testing other positive serum related to swine viral pathogens, this established ELISA demonstrated no cross-reactivity to them. Further, the overall rate of coincidence of this ELISA was calculated at $96.74 \%$ compared with IFA, proving that the diagnostic sensitivity and specificity of this ELISA method were favorable.

Of the numerous pathogens which can cause swine viral diarrhea, PEDV, TGEV, and PoRV account for the largest proportion [26]. In the present study, 16/149 anti-PoRV antibody positive sample and 27/195 anti-TGEV antibody positive samples were tested PEDV antibody positive, which indicated there may be co-infection of PEDV and other virus.

\section{Conclusions}

In conclusion, this established S1 indirect ELISA is capable of detecting serum antibodies against PEDV, and due to its high sensitivity and specificity, it could be applied for serological evaluation and indirect diagnosis of PEDV infection.

\section{Abbreviations}

CV: Coefficient of variation; ELISA: Enzyme-linked immunosorbent assay; IFA: Indirect immunoinfluscent assay; PEDV: Porcine epidemic diarrhea virus (PEDV); SD: Standard deviation; SN: Seroneutralization assay; TMB: Tetramethylbenzidine

\section{Funding}

This study was supported by the National Key Research and Development Program of China (2018YFD0500100), the National Natural Science Foundation of China (31702278, 31672574), the Jiangsu Agricultural Science and Technology Innovation Fund (CX(15)1056), the Postdoctoral Fund of Jiangsu Province (1501030C) and the Priority Academic Program Development of Jiangsu Higher Education Institutions (PAPD).
Availability of data and materials

The data analyzed during the current study are available from the corresponding author on reasonable request.

\section{Authors' contributions}

$\mathrm{HL}, \mathrm{KH}$ and $\mathrm{HF}$ designed the study. HL, HZ, LG and BL performed and collected data from experiment and analyzed data. $\mathrm{HL}, \mathrm{HZ}$ wrote the manuscript. All authors read and approved the final manuscript.

\section{Ethics approval}

This study was performed in accordance with the recommendations in the Guide for the Care and Use of Laboratory Animals of the Ministry of Health, China. All experimental protocols were approved by the Institutional Animal Care and Use Committee of Nanjing Agricultural University (No. SYXK20150057) and performed accordingly. Samples were collected only from animals for laboratory analyses, avoiding unnecessary pain and suffering of the animals. The owners gave their written consent for sample collection, and the locations where we sampled are not privately owned or protected in any way. The studies did not involve endangered or protected species.

Consent for publication

Not applicable.

\section{Competing interests}

The authors declare that they have no competing interests.

\section{Publisher's Note}

Springer Nature remains neutral with regard to jurisdictional claims in published maps and institutional affiliations.

\section{Author details}

'MOE Joint International Research Laboratory of Animal Health and Food Safety, College of Veterinary Medicine, Nanjing Agricultural University, Nanjing 210095, China. ${ }^{2}$ Institute of Veterinary Medicine, Jiangsu Academy of Agricultural Sciences, Nanjing 210014, China. ${ }^{3}$ Jiangsu Co-Innovation Center for the Prevention and Control of Important Animal Infectious Diseases and Zoonoses, Yangzhou University, Yangzhou 225009, China.

Received: 29 January 2018 Accepted: 13 August 2018 Published online: 20 August 2018

\section{References}

1. Hanke D, Pohlmann A, Sauter-Louis C, Hoper D, Stadler J, Ritzmann M, Steinrigl A, Schwarz BA, Akimkin V, Fux R, et al. Porcine epidemic diarrhea in 
Europe: in-detail analyses of disease dynamics and molecular epidemiology. Viruses. 2017;9(7):177.

2. Curry SM, Gibson KA, Burrough ER, Schwartz K, Yoon KJ, Gabler NK. Nursery pig growth performance and tissue accretion modulation due to porcine epidemic diarrhea virus or porcine deltacoronavirus challenge. J Anim Sci. 2017:95(1):173-81.

3. Kim O, Chae C. In situ hybridization for the detection and localization of porcine epidemic diarrhea virus in the intestinal tissues from naturally infected piglets. Vet Pathol. 2000;37(1):62-7.

4. Li B, Du L, Yu Z, Sun B, Xu X, Fan B, Guo R, Yuan W, He K. Poly (d,--lactide-coglycolide) nanoparticle-entrapped vaccine induces a protective immune response against porcine epidemic diarrhea virus infection in piglets. Vaccine. 2017;35(50):7010-7

5. Annamalai T, Lin CM, Gao X, Liu X, Lu Z, Saif LI, Wang Q. Cross protective immune responses in nursing piglets infected with a US spike-insertion deletion porcine epidemic diarrhea virus strain and challenged with an original US PEDV strain. Vet Res. 2017;48(1):61.

6. Wood EN. An apparently new syndrome of porcine epidemic diarrhoea. Vet Rec. 1977;100(12):243-4

7. Chung HC, Nguyen VG, Moon HJ, Lee JH, Park SJ, Lee GE, Kim HK, Noh YS, Lee $\mathrm{CH}$, Goede $\mathrm{D}$, et al. Isolation of porcine epidemic diarrhea virus during outbreaks in South Korea, 2013-2014. Emerg Infect Dis. 2015;21(12):2238-40.

8. Fan JH, Zuo YZ, Li JH, Pei LH. Heterogeneity in membrane protein genes of porcine epidemic diarrhea viruses isolated in China. Virus Genes. 2012;45(1):113-7.

9. Supekar VM, Bruckmann C, Ingallinella P, Bianchi E, Pessi A, Carfi A. Structure of a proteolytically resistant core from the severe acute respiratory syndrome coronavirus S2 fusion protein. Proc Natl Acad Sci U S A. 2004; 101(52):17958-63.

10. Chang SH, Bae JL, Kang TJ, Kim J, Chung GH, Lim CW, Laude H, Yang MS, Jang YS. Identification of the epitope region capable of inducing neutralizing antibodies against the porcine epidemic diarrhea virus. Molecules and cells. 2002;14(2):295-9.

11. Knuchel M, Ackermann M, Muller HK, Kihm U. An ELISA for detection of antibodies against porcine epidemic diarrhoea virus (PEDV) based on the specific solubility of the viral surface glycoprotein. Vet Microbiol. 1992;32(2):117-34.

12. Sun DB, Feng L, Shi HY, Chen JF, Liu SW, Chen HY, Wang YF. Spike protein region (aa 636789) of porcine epidemic diarrhea virus is essential for induction of neutralizing antibodies. Acta Virol. 2007;51(3):149-56.

13. Deng F, Ye G, Liu Q, Navid MT, Zhong X, Li Y, Wan C, Xiao S, He Q, Fu ZF, et al. Identification and comparison of receptor binding characteristics of the spike protein of two porcine epidemic diarrhea virus strains. Viruses. 2016;8(3):55.

14. Paudel S, Park JE, Jang H, Shin HJ. Comparison of serum neutralization and enzyme-linked immunosorbent assay on sera from porcine epidemic diarrhea virus vaccinated pigs. The Veterinary quarterly. 2014;34(4):218-23.

15. Lin H, Chen L, Gao L, Yuan X, Ma Z, Fan H. Epidemic strain YC2014 of porcine epidemic diarrhea virus could provide piglets against homologous challenge. Virol J. 2016;13:68.

16. Kim SH, Kim IJ, Pyo HM, Tark DS, Song JY, Hyun BH. Multiplex real-time RT-PCR for the simultaneous detection and quantification of transmissible gastroenteritis virus and porcine epidemic diarrhea virus. J Virol Methods. 2007; 146(1-2):172-7.

17. Li W, Li H, Liu Y, Pan Y, Deng F, Song Y, Tang X, He Q. New variants of porcine epidemic diarrhea virus, China, 2011. Emerg Infect Dis. 2012;18(8):1350-3.

18. Li Z, Chen F, Yuan Y, Zeng X, Wei Z, Zhu L, Sun B, Xie Q, Cao Y, Xue C, et al. Sequence and phylogenetic analysis of nucleocapsid genes of porcine epidemic diarrhea virus (PEDV) strains in China. Arch Virol. 2013;158(6):1267-73.

19. Oh JS, Song DS, Yang JS, Song JY, Moon HJ, Kim TY, Park BK. Comparison of an enzyme-linked immunosorbent assay with serum neutralization test for serodiagnosis of porcine epidemic diarrhea virus infection. J Vet Sci. 2005; 6(4):349-52.

20. Thachil A, Gerber PF, Xiao CT, Huang YW, Opriessnig T. Development and application of an ELISA for the detection of porcine deltacoronavirus lgG antibodies. PLoS One. 2015;10(4):e0124363.

21. Gerber PF, Gong Q, Huang YW, Wang C, Holtkamp D, Opriessnig T. Detection of antibodies against porcine epidemic diarrhea virus in serum and colostrum by indirect ELISA. Vet J. 2014;202(1):33-6.

22. Cruz DJ, Kim CJ, Shin HJ. Phage-displayed peptides having antigenic similarities with porcine epidemic diarrhea virus (PEDV) neutralizing epitopes. Virology. 2006;354(1):28-34.
23. Sun D, Feng L, Shi H, Chen J, Cui X, Chen H, Liu S, Tong Y, Wang Y, Tong G. Identification of two novel $B$ cell epitopes on porcine epidemic diarrhea virus spike protein. Vet Microbiol. 2008;131(1-2):73-81.

24. Jung K, Saif LJ. Porcine epidemic diarrhea virus infection: etiology, epidemiology, pathogenesis and immunoprophylaxis. Vet J. 2015; 204(2):134-43.

25. Poonsuk K, Gimenez-Lirola LG, Zhang J, Arruda P, Chen Q, Correa da Silva Carrion L, Magtoto R, Pineyro P, Sarmento L, Wang C, et al. Does circulating antibody play a role in the protection of piglets against porcine epidemic diarrhea virus? PLoS One. 2016;11(4):e0153041.

26. Lin CM, Gao X, Oka T, Vlasova AN, Esseili MA, Wang Q, Saif LJ. Antigenic relationships among porcine epidemic diarrhea virus and transmissible gastroenteritis virus strains. J Virol. 2015;89(6):3332-42.
Ready to submit your research? Choose BMC and benefit from:

- fast, convenient online submission

- thorough peer review by experienced researchers in your field

- rapid publication on acceptance

- support for research data, including large and complex data types

- gold Open Access which fosters wider collaboration and increased citations

- maximum visibility for your research: over $100 \mathrm{M}$ website views per year

At BMC, research is always in progress.

Learn more biomedcentral.com/submissions 